\title{
Several Factors Influencing the Stability of Extracted Species in Synergistic Extraction of Lanthanide(III) with Pivaloyltrifluoroacetone and 2,2'-Bipyridyl
}

\author{
Tadahisa Saito, Kazuaki Sato, Mitsunobu Miratsu, Izuru Matsubayashi, Masayuki Inoue, \\ and Yuko HaSEGAWA ${ }^{\dagger}$
}

Department of Chemistry, Faculty of Science, Science University of Tokyo, 1-3 Kagurazaka, Shinjuku, Tokyo 162-8601, Japan

\begin{abstract}
The stability constants and the hydration number of a complex between tris(pivaloyltrifluoroacetonato)lanthanide(III) $\left(\mathrm{LnA}_{3}\right)$ and 2,2'-bipyridyl (B), $\mathrm{LnA}_{3} \mathrm{~B}$, and the complexation heat were determined across the Ln series by a solventextraction technique, Karl Fischer coulometry, and calorimetry, successively. The number of water molecules released from $\mathrm{LnA}_{3}$ upon the complexation with $\mathrm{B}$ as well as the values of the stability constant increased along with increasing Ln atomic number to around Dy(III); via a maximum, it decreased. It is concluded that the largest stability constant of the complex of $\mathrm{Ho}$ (III) or this vicinity is derived from the strongest bond energy, due to the fitness between $\mathrm{LnA}_{3}$ and $\mathrm{B}$. This conclusion was supported by the trend of the variation of the entropy change as well as that of the hydration number across the Ln series.
\end{abstract}

(Received August 7, 2010; Accepted October 18, 2010; Published November 10, 2010)

\section{Introduction}

It is generally accepted that the extraction of lanthanides(III) (Lns(III)) is synergistically enhanced with most $\beta$-diketones (HA) and Lewis bases (B), due to complexation between $\operatorname{tris}(\beta$-diketonato $) \operatorname{Ln}(\mathrm{III}) \quad\left(\mathrm{LnA}_{3}\right)$ and $\mathrm{B} \cdot .^{1-11}$ The synergistic effectiveness is related to two process; the extraction of $\operatorname{Ln}(\mathrm{III})$ as $\mathrm{LnA}_{3}$ from the aqueous phase into the organic phase and complexation between $\mathrm{LnA}_{3}$ and $\mathrm{B}$ in the organic phase. Accordingly, the synergistic extraction constant, $K_{\text {ex } 31}=$ $\left[\mathrm{LnA}_{3} \mathrm{~B}\right]_{\mathrm{o}}\left[\mathrm{H}^{+}\right]^{3}\left[\mathrm{Ln}^{3+}\right]^{-1}[\mathrm{HA}]_{0}^{-3}[\mathrm{~B}]_{\mathrm{o}}^{-1}=K_{\mathrm{ex} 30} \times \overline{\beta_{1}}$, where $K_{\mathrm{ex} 30}$ is the extraction constant of $\mathrm{LnA}_{3}\left(K_{\mathrm{ex} 30}=\left[\mathrm{LnA}_{3}\right]_{\mathrm{o}}\left[\mathrm{H}^{+}\right]^{3}\left[\mathrm{Ln}^{3+}\right]^{-1}[\mathrm{HA}]_{0}{ }^{-3}\right)$ and $\bar{\beta}_{1}\left(=\left[\operatorname{LnA}_{3} \mathrm{~B}\right]_{\mathrm{o}}\left[\operatorname{LnA}_{3}\right]_{\mathrm{o}}{ }^{-1}[\mathrm{~B}]_{\mathrm{o}}{ }^{-1}\right)$, where the subscript "o" indicates the species in the organic phase; the lack of a subscript indicates the species in the aqueous phase. There are many reports that in synergistic extraction with HA and monodentate B, such as tributylphosphate ${ }^{1,2}$ and carboxylic acids, ${ }^{3-6}$ the extractability does not change much across the Ln series, although extraction with $\beta$-diketone alone increases along with increasing $\mathrm{Ln}$ atomic number. On the other hand, there are several reports that in extraction with $\mathrm{HA}$ and bidentate $\mathrm{B}$, such as 1,10-phenanthroline (phen) and 2,2'-bipyridyl (bpy), the extractability increases along with increasing $\mathrm{Ln}$ atomic number ${ }^{7-11}$ because of the formation of a more stable complex for heavier $\operatorname{Ln}(\mathrm{III})$, even if the same $\beta$-diketone is used in the extraction with both Lewis bases. The difference has been explained in terms of the variation pattern of the stability of the complexes formed between monodentate and bidentate Lewis bases across the Ln series; the former forms a less-stable complex, and the latter forms a more stable complex with $\mathrm{LnA}_{3}$ along with increasing $\mathrm{Ln}$ atomic number. To obtain some information about the different variation patterns of the extractability with monodentate and bidentate Lewis bases across the Ln series, the complexation heats of the extracted species, $\mathrm{LnA}_{3} \mathrm{~B}$, as well as the stability constants of $\mathrm{Ln}(\mathrm{tta})_{3}$ $(\mathrm{Htta}=2$-thenoyltrifluoroacetone $)$ adducts with phen $(\mathrm{B})^{10}$ in $\mathrm{CHCl}_{3}$ across the Ln series have been measured. The complexation heat varied from endothermic to exothermic along with increasing $\mathrm{Ln}$ atomic number. This suggests that phen forms a stronger bond with the heavier Lns(III). Besides from the variation of the entropy change across the Ln series, the involvement of water molecules coordinated to $\mathrm{Ln}$ (III) upon the extraction with $\beta$-diketone was suggested, and later it was proved by measuring the hydration number of $\operatorname{LnA}_{3} \mathrm{~B} \cdot{ }^{11-13}$ Decreasing stability constants of the $\operatorname{Ln}(\mathrm{tta})_{3}$ complex with a weak Lewis base was explained in relation to the released water molecules. ${ }^{6}$ Complexation of $\mathrm{Ln}(\mathrm{III})$ is strongly influenced by water molecules, either in aqueous solutions or in organic solvents, because Ln(III) is a typical hard Lewis acid, and has strong affinity to $\mathrm{O}$ donor atoms. When the relation of water molecules coordinating to $\mathrm{LnA}_{3}$ and the strength of Lewis basicity of ligands to the complexation of $\mathrm{LnA}_{3}$ is elucidated, it would offer effective information to separate a proper $\mathrm{Ln}(\mathrm{III})$ among all Lns(III) selectively. Thus, in the present work, pivaloyltrifluoroacetone (Hpta) and bpy have been selected as $\mathrm{HA}$ and $\mathrm{B}$, respectively, and the complexation between $\mathrm{LnA}_{3}$ and $\mathrm{B}$ in $\mathrm{CHCl}_{3}$ has been studied systematically by measuring the stability constants, the hydration number of $\operatorname{LnA}_{3} \mathrm{~B}$, and also the complexation heats across the Ln series.

$\dagger$ To whom correspondence should be addressed.

E-mail: yhasegaw@rs.kagu.tus.ac.jp 


\section{Experimental}

\section{Reagents and chemicals}

All reagents were of analytical grade. Hpta and bpy were purchased from Dojin Laboratories, and Nacalai Tesque, Inc. respectively. Lanthanide(III) oxides (purity >99.9\%) were purchased from the following companies: from Shin-Etsu Chemical Co. (La and Gd), Nacalai Tesque (Nd), Inc. and Mitsuwa Chemicals (other Lns). The Ln(III) aqueous solutions were prepared by dissolving the respective oxide in a little excess of perchloric acid. The exact concentration of $\operatorname{Ln}(\mathrm{III})$ was determined by titration with an EDTA solution at $\mathrm{pH} 5$ using Xylenol Orange as an indicator. Chloroform was washed with deionized water just before use. Other reagents were used without purification.

\section{Procedure}

Most experiments were performed in a thermostatted room at $298 \pm 1 \mathrm{~K}$. The total ionic concentration was adjusted to $0.1 \mathrm{M}$ ( $\left.1 \mathrm{M}=1 \mathrm{~mol} \mathrm{dm}^{-3}\right)$ with sodium perchlorate.

Extraction of Ln(III) with Hpta and/or bpy. Six milliliters of aqueous solution containing $\operatorname{Ln}(\mathrm{III})\left(2 \times 10^{-5}-4 \times 10^{-3} \mathrm{M}\right)$ were vigorously shaken with an identical volume of a chloroform solution containing Hpta $(0.02-0.1 \mathrm{M})$ and/or bpy $(0-0.03 \mathrm{M})$ for $1 \mathrm{~h}$. Then, two phases were centrifuged. Lanthanide(III) remaining in chloroform was back-extracted into $0.1 \mathrm{M}$ perchloric acid, and Ln(III) transferred into aqueous phases was diluted with $0.1 \mathrm{M} \mathrm{HClO}_{4}$ by a factor of 10 to protect it from any influence of the $\mathrm{Na}$ ion. Then, the concentration was measured by ICP-OES (Hitachi P-4000). The distribution ratio, $D$, was denoted as the total concentration ratio of $\mathrm{Ln}(\mathrm{III})$ between both phases. The hydrogen ion concentration $\left(\mathrm{p} C_{\mathrm{H}}=\right.$ $\left.-\log \left[\mathrm{H}^{+}\right]\right)$at equilibrium was measured potentiometrically using a solution containing $1.00 \times 10^{-2} \mathrm{M}$ perchloric acid at $0.1 \mathrm{M}$ $(\mathrm{H}, \mathrm{Na}) \mathrm{ClO}_{4}$ as the standard $\mathrm{p} C_{\mathrm{H}}=2.00$ (Corning, Model 445). Hydration number of Ln(pta) $)_{3}$ bpy. The procedure was performed in a similar way as described elsewhere. ${ }^{11-13}$ Lanthanide(III) was extracted from $6.0 \mathrm{~mL}$ of a $0.030 \mathrm{M} \mathrm{Ln}$ (III) perchlorate solution at $\mathrm{p} C_{\mathrm{H}}=4$ to 6 (for the lighter $\mathrm{Ln}(\mathrm{III})$, e.g., $\mathrm{La}(\mathrm{III})$ and $\operatorname{Pr}(\mathrm{III})$, higher $\mathrm{p} C_{\mathrm{H}} 5.6-5.7$, for the heavier ones, e.g., $\mathrm{Yb}(\mathrm{III})$ and $\mathrm{Lu}(\mathrm{III})$, lower $\left.\mathrm{p}_{\mathrm{H}} 4.4-4.7\right)$ into an equal volume of $\mathrm{CHCl}_{3}$ containing 0.06 or $0.08 \mathrm{M} \mathrm{Hpta}$ and/or $0.02 \mathrm{M}$ bpy. The exact concentration of $\mathrm{Ln}(\mathrm{III})$ extracted into $\mathrm{CHCl}_{3}$ was determined by ICP/OES. The water content in $\mathrm{CHCl}_{3}$ was measured by Coulometric Karl Fischer titration (Hiranuma Sangyo Co., Ltd. Model AQ-7).

Calorimetric titration of Ln(pta $)_{3}$ with bpy. Eight milliliters of an aqueous solution containing $\operatorname{Ln}(\mathrm{III})(0.02 \mathrm{M})$ at $\mathrm{p} C_{\mathrm{H}} 5-6$ were shaken with an identical volume of $\mathrm{CHCl}_{3}$ containing Hpta $(0.03 \mathrm{M})$ for $1 \mathrm{~h}$. After centrifuging, a portion of the organic phase was diluted as much as 5 or 10 times with $\mathrm{CHCl}_{3}$, and it was then used as a sample solution. Into a sample solution of $3.00 \mathrm{~mL}$ placed in a glass vessels, $3.00 \times 10^{-2} \mathrm{M}$ bpy solution of $10.0 \mu \mathrm{L}$ was injected ten times. The heat change at each injection was measured by an isothermal titration microcalorimeter (TAM 2277; Thermometric AB, Sweden) controlled by Digitam 4.1 software.

\section{Results and Discussion}

Before studying the extraction of $\mathrm{Ln}(\mathrm{III})$, the dissociation and distribution constants of bpy (=B) were determined; A chloroform solution containing a constant concentration of $\mathrm{B}$ was shaken with $0.1 \mathrm{M} \mathrm{NaClO}_{4}$ at different $\mathrm{p} C_{\mathrm{H}}$ values until they attained at extraction equilibrium. The concentration of $\mathrm{B}$ remained in $\mathrm{CHCl}_{3}$, and that transfered into aqueous phase were determined by measuring the absorbance of the $\mathrm{CHCl}_{3}$ directly and after being adjusted $\mathrm{p} C_{\mathrm{H}}$ to basic and reextracted into $\mathrm{CHCl}_{3}$ at $283.4 \mathrm{~nm}$ (the molar absorptivity, $1.44 \times 10^{4}$ ), respectively. At the same time $\mathrm{p} C_{\mathrm{H}}$ was also measured. When $\mathrm{B}$ distributes between organic and aqueous phases, the distribution ratio of $\mathrm{B}$ can be represented as

$$
D=\frac{[\mathrm{B}]_{\mathrm{o}}}{[\mathrm{B}]+\left[\mathrm{HB}^{+}\right]} \text {. }
$$

Introducing the dissociation constant $\left(K_{\mathrm{a}}^{\prime}=\left[\mathrm{H}^{+}\right][\mathrm{B}]\left[\mathrm{HB}^{+}\right]^{-1}\right)$ and the distribution constant $\left(K_{\mathrm{d}}{ }^{\prime}=[\mathrm{B}]_{\mathrm{o}}[\mathrm{B}]^{-1}\right)$ into Eq. (1),

$$
\log D=\log K_{\mathrm{d}}^{\prime}-\log \left(1+\left[\mathrm{H}^{+}\right] K_{\mathrm{a}}{ }^{-1}\right)
$$

is obtained. The value of $\mathrm{p} K_{\mathrm{a}}^{\prime}$ was also determined by analyzing the data based on the mass balance of $\mathrm{B}$ and $\mathrm{H}^{+}$when a $\mathrm{B} / \mathrm{CHCl}_{3}$ solution was shaken with $0.1 \mathrm{M} \mathrm{NaClO}_{4}$ at various $\mathrm{p} C_{\mathrm{H}}$ values. The $\mathrm{p} K_{\mathrm{a}}^{\prime}$ values determined by both methods agreed well. As $\log K_{\mathrm{d}}^{\prime}, 2.66 \pm 0.03$ and as $\mathrm{p} K_{\mathrm{a}}^{\prime}, 4.31 \pm 0.01$ were obtained, respectively.

\section{Extraction of Ln(III) with Hpta and/or bpy}

Plots of $\log D$, the distribution ratio of $\operatorname{Ln}(\mathrm{III})$, against the Hpta (HA) concentration at a constant $\mathrm{p} C_{\mathrm{H}}$ as well as that against $\mathrm{p} C_{\mathrm{H}}$ at a constant $\mathrm{HA}$ concentration $(0.10$ or $0.20 \mathrm{M})$ showed straight lines having a slope of +3 . It was confirmed that three molecules of proton as well as HA participated for the extraction of $\operatorname{Ln}(\mathrm{III}) ; \log D$ changes linearly to $3 \mathrm{p} C_{\mathrm{H}}$, and also to $3 \log [\mathrm{HA}]_{0}$. Accordingly the extraction of $\mathrm{LnA}_{3}$ and the extraction constant, $K_{\text {ex }}$, described in "Introduction" can be represented as follows:

$$
\begin{aligned}
& \mathrm{Ln}^{3+}+3 \mathrm{HA}(\mathrm{o}) \rightleftharpoons \mathrm{LnA}_{3}(\mathrm{o})+3 \mathrm{H}^{+}, \\
& K_{\mathrm{ex}}=D\left[\mathrm{H}^{+}\right]^{3}[\mathrm{HA}]_{\mathrm{o}}{ }^{-3},
\end{aligned}
$$

i.e., $\log K_{\mathrm{ex}}=\log D-3\left(\mathrm{p} C_{\mathrm{H}}+\log [\mathrm{HA}]_{\mathrm{o}}\right)$. The concentration of $\mathrm{HA}$ in the organic phase can be calculated from the mass balance of the $\beta$-diketone as follows:

$$
\begin{aligned}
& A_{\mathrm{T}}=[\mathrm{HA}]+[\mathrm{HA}]_{\mathrm{o}}+\left[\mathrm{A}^{-}\right]+3\left[\mathrm{LnA}_{3}\right]_{\mathrm{o}}, \\
& {[\mathrm{HA}]_{0}=\frac{A_{\mathrm{T}}-3\left[\mathrm{LnA}_{3}\right]_{\mathrm{o}}}{K_{\mathrm{d}}^{-1}\left(1+K_{\mathrm{a}} /\left[\mathrm{H}^{+}\right]\right)+1},}
\end{aligned}
$$

where $K_{\mathrm{d}}\left(\log K_{\mathrm{d}}=2.51\right)$ and $K_{\mathrm{a}}\left(\mathrm{p} K_{\mathrm{a}}=7.01\right)$ are the distribution constant $\left(K_{\mathrm{d}}=[\mathrm{HA}]_{\mathrm{o}} /[\mathrm{HA}]\right)$ and the dissociation constant of Hpta $\left(K_{\mathrm{a}}=\left[\mathrm{H}^{+}\right]\left[\mathrm{A}^{-}\right][\mathrm{HA}]^{-1}\right)$, respectively. ${ }^{14}$ The extraction constants of $\mathrm{LnA}_{3}$ obtained in the present study are listed in Table 1 together with the standard deviation. The constant increases along with increasing Ln atomic number.

When $\mathrm{Ln}(\mathrm{III})$ was extracted with HA and B, the extractability was remarkably enhanced. Figure 1 shows several examples of the correlation between the distribution ratio and the concentration of $\mathrm{B}$ at equilibrium, where the concentration of the protons and HA was normalized. Since the slope of the plot of $\log \left(D\left[\mathrm{H}^{+}\right]^{3}[\mathrm{HA}]_{\mathrm{o}}^{-3}\right)$ vs. $\log [\mathrm{B}]_{\mathrm{o}}$ was unity for all $\operatorname{Lns}(\mathrm{III})$ studied, and the distribution ratio was much higher in the extraction with $\mathrm{HA}$ and $\mathrm{B}$ at a same $\mathrm{p} C_{\mathrm{H}}$ and $[\mathrm{HA}]_{\mathrm{o}}$ than that with HA alone, the first stability constant of the $\mathrm{LnA}_{3}$ adduct with $\mathrm{B}, \bar{\beta}_{1}$, can be obtained from the following equation by 
Table 1 Extraction constant $\left(K_{\mathrm{ex}}\right)$ of $\mathrm{Ln}(\mathrm{pta})_{3}$ and stability constants, hydration number of $\mathrm{LnA}_{3} \mathrm{~B} n \mathrm{H}_{2} \mathrm{O}$, and the number of water molecules released from $\mathrm{LnA}_{3}$ upon complexation

\begin{tabular}{lcccc}
\hline $\mathrm{Ln}(\mathrm{III})$ & $\log K_{\mathrm{ex}}^{\mathrm{a}} \pm \sigma$ & $\log \bar{\beta}_{1}^{\mathrm{b}} \pm \sigma$ & $n \pm \sigma$ & $n-n_{0}$ \\
\hline $\mathrm{La}$ & $-13.05 \pm 0.06$ & $4.5 \pm 0.1$ & $0.30 \pm 0.03$ & 1.90 \\
$\mathrm{Pr}$ & $-11.78 \pm 0.08$ & $5.19 \pm 0.08$ & $0.17 \pm 0.03$ & 1.97 \\
$\mathrm{Nd}$ & $-11.42 \pm 0.05$ & $5.27 \pm 0.08$ & $0.20 \pm 0.03$ & 1.99 \\
$\mathrm{Sm}$ & $-10.61 \pm 0.05$ & $5.61 \pm 0.05$ & $-^{\mathrm{c}}$ & - \\
$\mathrm{Eu}$ & $-10.48 \pm 0.05$ & $5.76 \pm 0.06$ & $0.15 \pm 0.04$ & 2.15 \\
$\mathrm{Gd}$ & $-10.58 \pm 0.08$ & $5.8 \pm 0.1$ & $0.17 \pm 0.01$ & 2.39 \\
$\mathrm{~Tb}$ & $-10.12 \pm 0.09$ & $5.9 \pm 0.1$ & $0.14 \pm 0.02$ & 2.35 \\
$\mathrm{Dy}$ & $-10.04 \pm 0.08$ & $6.05 \pm 0.09$ & - & - \\
$\mathrm{Ho}$ & $-9.92 \pm 0.06$ & $6.03 \pm 0.07$ & $0.11 \pm 0.03$ & 2.29 \\
$\mathrm{Er}$ & $-9.64 \pm 0.02$ & $5.97 \pm 0.04$ & - & - \\
$\mathrm{Tm}$ & $-9.34 \pm 0.04$ & $5.89 \pm 0.05$ & $0.12 \pm 0.02$ & 2.06 \\
$\mathrm{Yb}$ & $-9.07 \pm 0.03$ & $5.79 \pm 0.05$ & $0.12 \pm 0.02$ & 1.86 \\
$\mathrm{Lu}$ & $-9.17 \pm 0.06$ & $5.75 \pm 0.05$ & $0.10 \pm 0.02$ & 1.96 \\
\hline
\end{tabular}

a. $K_{\mathrm{ex}}=\left[\mathrm{LnA}_{3}\right]_{\mathrm{o}}\left[\mathrm{H}^{+}\right]^{3}\left[\mathrm{Ln}^{3+}\right]^{-1}[\mathrm{HA}]_{\mathrm{o}}^{-3}$.

b. $\bar{\beta}_{1}=\left[\operatorname{LnA}_{3} \mathrm{~B}\right]_{\mathrm{o}}\left(\left[\operatorname{LnA}_{3}\right]_{\mathrm{o}}[\mathrm{B}]_{\mathrm{o}}\right)^{-1}$.

c. No data.

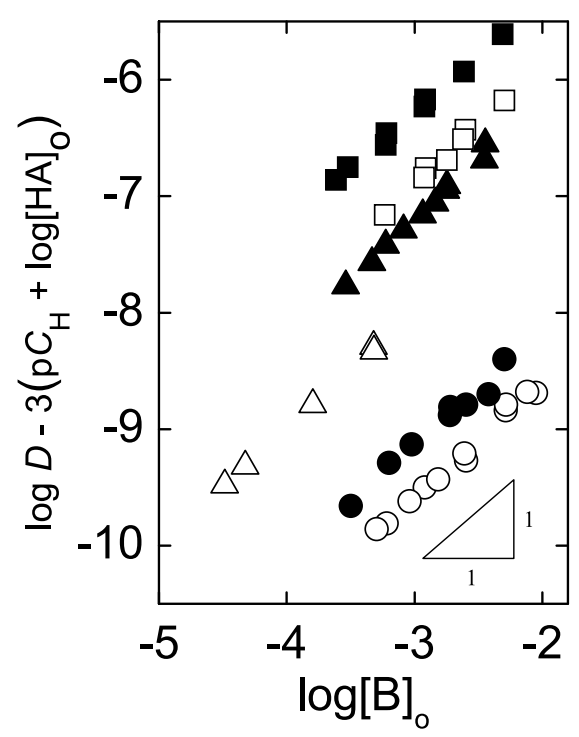

Fig. 1 Extraction enhancement of Ln(III) with Hpta in the presence of bipyridyl. $\bigcirc$, Pr; $\bullet$, Nd; $\triangle$, Sm; $\boldsymbol{\Delta}, \mathrm{Tb} ; \square, \mathrm{Ho} ; \mathbf{\square}, \mathrm{Yb}$.

assuming the dominant extracted species being as only $\operatorname{LnA}_{3} B$ :

$$
D=\frac{K_{\mathrm{ex}} \bar{\beta}_{1}[\mathrm{~B}]_{\mathrm{o}}[\mathrm{HA}]_{\mathrm{o}}{ }^{3}}{\left[\mathrm{H}^{+}\right]^{3}} .
$$

Here, $[B]_{0}$ can be calculated from the mass balance of the corresponding species as

$$
\begin{aligned}
& B_{\mathrm{T}}=\left[\mathrm{HB}^{+}\right]+[\mathrm{B}]+[\mathrm{B}]_{\mathrm{o}}+\left[\operatorname{LnA}_{3} \mathrm{~B}\right]_{\mathrm{o}} \\
& {[\mathrm{B}]_{\mathrm{o}}=\frac{B_{\mathrm{T}}-\left[\operatorname{LnA}_{3} \mathrm{~B}\right]_{\mathrm{o}}}{K_{\mathrm{d}^{\prime}}{ }^{-1}\left(1+\frac{\left[\mathrm{H}^{+}\right]}{K_{\mathrm{a}}^{\prime}}\right)+1}}
\end{aligned}
$$

The stability constants of the complex formed between $\mathrm{LnA}_{3}$ and $\mathrm{B}$ are also listed in Table 1 . The constants increase with increasing atomic number from light to the middle of the Ln
Table 2 Water content in $\mathrm{CHCl}_{3}$ containing the $\mathrm{Ho}(\mathrm{pta})_{3}$ adduct

\begin{tabular}{|c|c|c|c|c|c|c|c|}
\hline \multicolumn{4}{|c|}{ Extraction condition } & \multicolumn{3}{|c|}{ Concentration at equilibrium } & \\
\hline $\begin{array}{c}{\left[\mathrm{Ho}\left(\mathrm{ClO}_{4}\right)_{3}\right]_{\mathrm{T}} /} \\
\mathrm{mM}\end{array}$ & $\mathrm{p} C_{\mathrm{H}}$ & $\begin{array}{c}{[\mathrm{HA}]_{\mathrm{T}} /} \\
\mathrm{mM}\end{array}$ & $\begin{array}{l}{[\mathrm{B}]_{\mathrm{T}} /} \\
\mathrm{mM}\end{array}$ & $\begin{array}{c}\mathrm{Ho}(\mathrm{III})]_{\mathrm{o}, \mathrm{T}} / \\
\mathrm{mM}\end{array}$ & $\begin{array}{c}{\left[\mathrm{H}_{2} \mathrm{O}\right]_{\mathrm{o}, \mathrm{T}} \mathrm{T}} \\
\mathrm{mM}\end{array}$ & $\begin{array}{c}{\left[\mathrm{H}_{2} \mathrm{O}\right]_{\mathrm{CHCl}} /} \\
\mathrm{mM}\end{array}$ & \\
\hline 31.1 & 5.5 & 80.0 & 26.0 & 25.9 & 73.1 & 71.4 & 0.07 \\
\hline 31.1 & 4.9 & 80.0 & 26.0 & 25.8 & 74.5 & 71.6 & 0.11 \\
\hline 31.1 & 4.9 & 80.0 & 26.0 & 25.3 & 75.3 & 71.7 & 0.14 \\
\hline 31.1 & 5.0 & 80.0 & 26.0 & 25.8 & 75.2 & 71.4 & 0.15 \\
\hline 31.6 & 5.2 & 60.0 & 19.5 & 19.5 & 72.9 & 71.4 & 0.08 \\
\hline 31.6 & 4.9 & 60.0 & 19.5 & 18.9 & 73.6 & 71.6 & 0.11 \\
\hline 31.6 & 5.1 & 60.0 & 19.5 & 19.3 & 74.0 & 71.6 & 0.12 \\
\hline 31.6 & 5.0 & 60.0 & 19.5 & 18.9 & 74.1 & 71.7 & 0.13 \\
\hline
\end{tabular}
with bpy prepared by solvent extraction and the hydration number of $\mathrm{Ho}(\mathrm{pta})_{3}$ obtained

series, although in a more detailed observation, the constant had a maximum in the middle of the $\mathrm{Ln}$ series and then they gradually decreased. This point, in other words, the increase of the stability constants along with increasing Ln atomic number, is quite different from the variation of the constant of the monodentate Lewis base complex, because they generally decrease. When the reason why the stability constant increases along with increasing $\mathrm{Ln}$ atomic number and also the constant gives a maximum in a vicinity of $\mathrm{Ho}(\mathrm{III})$ is elucidated, the selective extraction of a certain Ln(III) might be possible. Then, as the next step, the residual hydration number of $\mathrm{LnA}_{3} \mathrm{~B}$ and the complexation heat were measured.

Effect of water molecules coordinated to Lns(III) on complexation bewteen $\mathrm{Ln}(\mathrm{pta})_{3}$ and bpy

When an aqueous solution containing $0.03 \mathrm{M} \mathrm{Ln}(\mathrm{III})$ at $\mathrm{p} C_{\mathrm{H}} 5$ was shaken with a $\mathrm{CHCl}_{3}$ solution consisting of $8 \times 10^{-2} \mathrm{M} \mathrm{HA}$ and $2.6 \times 10^{-2} \mathrm{M} \mathrm{B}$, almost $2.5 \times 10^{-2} \mathrm{M} \mathrm{Ln}$ (III) was extracted. The residual hydration number was calculated from dividing concentration of water coordinated to $\mathrm{Ln}(\mathrm{III})$, with the concentration of $\mathrm{Ln}(\mathrm{III})$ extracted into the $\mathrm{CHCl}_{3}$, i.e.,

$$
n=\frac{\left[\mathrm{H}_{2} \mathrm{O}\right]_{\mathrm{o}, \text { total }}-\left[\mathrm{H}_{2} \mathrm{O}\right]_{\mathrm{CHCl}_{3}}}{[\mathrm{Ln}(\mathrm{IIII})]_{\mathrm{o}}},
$$

where $\left[\mathrm{H}_{2} \mathrm{O}\right]_{\text {o,total }}$ is the water concentration in $\mathrm{CHCl}_{3}$ extracted $\mathrm{Ln}(\mathrm{III})$ and $\left[\mathrm{H}_{2} \mathrm{O}\right]_{\mathrm{CHCl}_{3}}$ is the background, i.e., saturated water solubility in $\mathrm{CHCl}_{3}$. A typical example of the experimental data to obtain the hydration number of $\operatorname{LnA}_{3} \mathrm{~B}$ is given in Table 2 . The residual hydration numbers of $\mathrm{LnA}_{3} \mathrm{~B}, n$, across the $\mathrm{Ln}$ series are also listed in Table 1. Similar to the hydration number of $\mathrm{Ln}(\mathrm{tta})_{3}$ phen $^{13}$ and $\mathrm{Ln}(\text { pta })_{3}$ bpy, ${ }^{11}$ where $\mathrm{Ln}$ (III) is $\mathrm{La}(\mathrm{III})$ and $\mathrm{Lu}(\mathrm{III})$, almost all water molecules coordinated to $\mathrm{Ln}(\mathrm{pta})_{3}$ are removed from $\operatorname{Ln}(\mathrm{pta})_{3}$ upon complexation with bpy. In the last column in Table 1 , the number of water molecules released from $\mathrm{LnA}_{3}$ upon complexation between $\mathrm{LnA}_{3}$ and $\mathrm{B}$ is given. The hydration number, $n_{0}$, is the number of water molecules accompanied by $\operatorname{Ln}\left(\mathrm{pta}_{3}{ }_{3}{ }^{12}\right.$ The number of water molecules released, which is obtained as a balance of the hydration number between $\mathrm{Ln}(\mathrm{pta})_{3}$ and $\mathrm{Ln}(\mathrm{pta})_{3}$ bpy, increases gradually among light Lns(III), via the maximum among the middle of the series, it then decreases. The variation in the number of water molecules released would be related to the variation in the charge density, the size and coordination number of $\operatorname{Ln}(\mathrm{III})$. As can be seen from Table 1, the trend of the change in number of the water molecules released is similar to that in the stability constants of $\mathrm{LnA}_{3} \mathrm{~B}$. The variation of the stability constants 
Table 3 Example of calorimetric titration data

\begin{tabular}{cccc}
\hline Total titrant $/ \mathrm{mL}$ & $Q / \mathrm{mJ}$ & $m_{\mathrm{Yb}(\mathrm{pta}) \mathrm{B}} / \mu \mathrm{mol}$ & $-\Delta H / \mathrm{kJ} \mathrm{mol}^{-1}$ \\
\hline 0.0099 & 5.49 & 0.298 & 18.4 \\
0.0199 & 11.6 & 0.596 & 20.6 \\
0.0298 & 17.9 & 0.894 & 21.1 \\
0.0398 & 24.0 & 1.19 & 20.5 \\
0.0497 & 30.4 & 1.49 & 21.6 \\
0.0597 & 36.5 & 1.78 & 21.0 \\
0.0696 & 41.8 & 2.04 & 19.9 \\
0.0796 & 44.1 & 2.21 & 14.0 \\
0.0895 & 44.5 & 2.24 & 12.7 \\
\hline
\end{tabular}

Initial conditions: cup contents, $\left[\mathrm{Yb}(\mathrm{pta})_{3}\right]=0.756 \mathrm{mM}$; volume, $3.00 \mathrm{~mL}$; titrant, $30.1 \mathrm{mM}$ bpy/ $\mathrm{CHCl}_{3}$.

across the Ln series can be qualitatively explained in terms of the entropy change derived from the number of released water molecules. Since the stability constants, or the free energy change, $-\Delta G$, are consisted of the enthalpy change and the entropy change, $-\Delta G=-\Delta H+T \Delta S$, at the next stage, the complexation heats of $\mathrm{LnA}_{3}$ with $\mathrm{B}$ are measured.

\section{Calorimetric titration of Ln(pta $)_{3}$ with bpy}

In advance to measure the complexation heat, it was tried to measure the background heat change; titration with $\mathrm{CHCl}_{3}$ to a $\mathrm{CHCl}_{3}$ solution containing $\mathrm{Hpta}$ or bpy was performed, i.e., $\mathrm{CHCl}_{3}$ was injected into $\mathrm{CHCl}_{3}$, bpy/CHCl 3 , and $\mathrm{Hpta} / \mathrm{CHCl}_{3}$. Further, the titration was carried out along with the injection of bpy/ $\mathrm{CHCl}_{3}$ into $\mathrm{CHCl}_{3}$ or $\mathrm{Hpta} / \mathrm{CHCl}_{3}$. Some heat was involved when each $10 \mu \mathrm{L}$ of the $\mathrm{CHCl}_{3}$ solution was dropped 10 times into $3.0 \mathrm{~mL}$ of the $\mathrm{CHCl}_{3}$ solution in the reaction vessel at $0.5 \mu \mathrm{L} / \mathrm{s}$. As the average, heat of $0.2 \mathrm{~mJ}$ at each drop was involved into all of the injections measured. This means that the heat is generated by mechanical mixing, and the heat involving the interaction between bpy and Hpta or by the dilution of bpy is much smaller.

Table 3 gives the titration data when a $0.030 \mathrm{M}$ bpy solution was injected at $0.5 \mu \mathrm{L} / \mathrm{s}$ into a $0.756 \mathrm{mM} \mathrm{Yb(pta)_{3 }}$ chelate chloroform solution of $3.00 \mathrm{~mL}$. The calorimetric titration was repeated several times for each $\mathrm{Ln}(\mathrm{III})$. Titration data for several Lns(III) are shown in Fig. 2; the heat emitted was plotted as a function of the substance amounts of the complex in the solution. The heat varied from endothermic to exothermic along with increasing Ln atomic number. The emitted heat changed linearly in the substance amounts of the complex in the solution, except for the highest region. The slope should be the complexation heat or the enthalpy change:

$$
Q=-\Delta H \times m,
$$

where $m$ is the total number moles of the first adduct in the solution. The value $m$ was calculated as follows:

$$
\begin{aligned}
& M_{\mathrm{T}}=\left[\operatorname{LnA}_{3}\right]_{\mathrm{o}}+\left[\operatorname{LnA}_{3} \mathrm{~B}\right]_{\mathrm{o}}=\left[\operatorname{LnA}_{3} \mathrm{~B}\right]_{\mathrm{o}}\left(1+\bar{\beta}_{1}^{-1}[\mathrm{~B}]_{\mathrm{o}}^{-1}\right), \\
& B_{\mathrm{T}}=[\mathrm{B}]_{\mathrm{o}}+\left[\mathrm{LnA}_{3} \mathrm{~B}\right]_{\mathrm{o}} .
\end{aligned}
$$

Then, the bpy concentration at equilibrium can be represented as

$$
[\mathrm{B}]_{\mathrm{o}}=\frac{\left(B_{\mathrm{T}}-M_{\mathrm{T}}\right) \bar{\beta}_{1}-1+\sqrt{\left(1-\left(B_{\mathrm{T}}-M_{\mathrm{T}}\right) \bar{\beta}_{1}\right)^{2}+4 \bar{\beta}_{1} B_{\mathrm{T}}}}{2 \bar{\beta}_{1}} .
$$

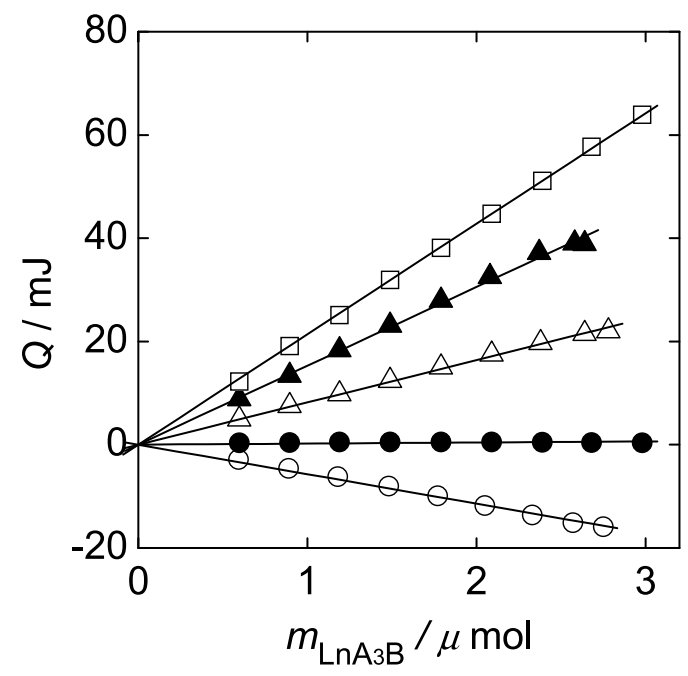

Fig. 2 Total heat emitted in the injection of bpy into a $\mathrm{Ln}(\mathrm{pta})_{3} / \mathrm{CHCl}_{3}$ solution $(Q)$ as a function of the number of moles of the complex formed between $\operatorname{Ln}(p t a)_{3}$ and bpy $\left(\mathrm{m}_{\mathrm{LnA}_{\mathrm{B}} \mathrm{B}}\right)$. The solid lines were calculated by using $-\Delta H$ in Table 4 , according to $Q=-\Delta H \times m$. $\bigcirc$, Nd;, Gd; $\triangle$, Dy; $\mathbf{\wedge}, \mathrm{Er} ; \square$, Lu.

Table 4 Thermodynamic parameters in forming the $\operatorname{Ln}(\mathrm{pta})_{3}$ adduct with bpy in $\mathrm{CHCl}_{3}$

\begin{tabular}{ccrc}
\hline $\mathrm{Ln}(\mathrm{III})$ & $\begin{array}{c}-\Delta G \pm \sigma / \\
\mathrm{kJ} \mathrm{mol}^{-1}\end{array}$ & $\begin{array}{c}-\Delta H \pm \sigma / \\
\mathrm{kJ} \mathrm{mol}^{-1}\end{array}$ & $\begin{array}{c}T \Delta S \pm \sigma / \\
\mathrm{kJ} \mathrm{mol}^{-1}\end{array}$ \\
\hline $\mathrm{La}$ & $25.7 \pm 0.6$ & $-11.3 \pm 0.7$ & $36.9 \pm 0.9$ \\
$\mathrm{Pr}$ & $29.6 \pm 0.5$ & $-5.6 \pm 0.6$ & $35.2 \pm 0.8$ \\
$\mathrm{Nd}$ & $30.1 \pm 0.5$ & $-5.5 \pm 0.8$ & $35.5 \pm 0.9$ \\
$\mathrm{Sm}$ & $32.1 \pm 0.3$ & $-3.8 \pm 0.9$ & $35.9 \pm 0.9$ \\
$\mathrm{Eu}$ & $32.9 \pm 0.3$ & $-0.8 \pm 1.0$ & $33.7 \pm 1.0$ \\
$\mathrm{Gd}$ & $33.3 \pm 0.6$ & $0.4 \pm 1.0$ & $32.8 \pm 1.1$ \\
$\mathrm{~Tb}$ & $33.8 \pm 0.6$ & $2.0 \pm 0.3$ & $31.8 \pm 0.7$ \\
$\mathrm{Dy}$ & $34.6 \pm 0.5$ & $8.2 \pm 0.7$ & $26.4 \pm 0.9$ \\
$\mathrm{Ho}$ & $34.4 \pm 0.3$ & $11.0 \pm 0.9$ & $23.4 \pm 0.9$ \\
$\mathrm{Er}$ & $34.1 \pm 0.2$ & $16.0 \pm 0.9$ & $18.1 \pm 0.9$ \\
$\mathrm{Tm}$ & $33.6 \pm 0.3$ & $19.0 \pm 0.9$ & $14.6 \pm 0.9$ \\
$\mathrm{Yb}$ & $33.0 \pm 0.3$ & $21.3 \pm 0.8$ & $11.8 \pm 0.9$ \\
$\mathrm{Lu}$ & $32.8 \pm 0.5$ & $22.4 \pm 0.7$ & $10.4 \pm 0.8$ \\
\hline
\end{tabular}

The moles of the $\mathrm{LnA}_{3}$ adduct formed with bpy, $m$, should be

$$
\begin{aligned}
& m=\left(B_{\mathrm{T}}-[\mathrm{B}]_{\mathrm{o}}\right)(3.00+v) 10^{-3} \\
& B_{\mathrm{T}}=[\mathrm{B}]_{\text {initial }} \times v /(3.00+v)
\end{aligned}
$$

and

$$
M_{\mathrm{T}}=[\mathrm{Ln}(\mathrm{III})]_{\text {initial }} \times 3.00 /(3.00+v),
$$

where $v$ is the volume $(\mathrm{mL})$ of the bpy solution added into the solution in the reaction vessel. The solid line for each plot in Fig. 2 was calculated from Eq. (11) using the obtained $-\Delta H$. All of the thermodynamic parameters obtained in the present work are listed in Table 4 . The change in the Gibbs free energy $(-\Delta G)$ was calculated according to $-\Delta G=R T \ln \bar{\beta}_{1}$ where $R$ is the gas constant, $8.313 \mathrm{~J} \mathrm{~K}^{-1} \mathrm{~mol}^{-1}$.

As can be seen from Table 4, the enthalpy change increases along with increasing $\mathrm{Ln}$ atomic number. Compared to the 
variation of the enthalpy change, that of the entropy change is small until around $\mathrm{Tb}$. The entropy change should decrease with turning a more rigid structure due to the formation of a chelate and increase with the release of water molecules. Due to the balance between the increase and the decrease, the entropy change is almost constant among light Lns, but around post Gd the ordering of the complex structure becomes dominant; that is, the size of $\operatorname{Ln}(\mathrm{III})$ is going to match to the distance between $\mathrm{N}$ and $\mathrm{N}$ in bpy. This idea is supported by the trend in the variation of the enthalpy change; the enthalpy change consists of the heat involving the dehydration (endothermic) and the bond formation between $\mathrm{LnA}_{3}$ and $\mathrm{B}$ (exothermic). Among light lanthanides, since the energy to dehydrate may be more dominant than that to form a new bond, $-\Delta H$ should be endothermic and the degree of the change is not large. In the middle of the series, the coordination number turns from 9 to 8 , so that change in the charge density and the size is much larger than that estimated from the uniform coordination number. Due to the fitness of the size of $\mathrm{Ln}(\mathrm{III})$ to the distance between $\mathrm{N}$ and $\mathrm{N}$ in bpy, heavier Lns(III) are more favorable for $-\Delta H$. In the heaviest ones, since the fitness between $\mathrm{Ln}$ (III) and bpy becomes worse, the increment should become smaller, although the charge density still gradually increases with increasing $\mathrm{Ln}$ atomic number. The smaller number of the released water molecules among the heaviest Lns(III) also functions unfavorably for an entropy change. This should be a reason why the stability constant of $\mathrm{LnA}_{3} \mathrm{~B}$ is the largest for around Ho(III) among the Ln series.

\section{Conclusions}

From measurement of $-\Delta G,-\Delta H$, and $T \Delta S$ upon complexation between $\operatorname{Ln}(\mathrm{pta})_{3}$ and bpy, and also the number of dehydrated water molecules across Ln series, it was found that the stability of the $\operatorname{Ln}(\mathrm{pta})_{3}$ bpy complex is mostly influenced by the fitness between the size of $\mathrm{Ln}(\mathrm{III})$ and the distance between $\mathrm{N}$ and $\mathrm{N}$ in bpy as well as the number of released water molecules upon complexation between $\operatorname{Ln}(\mathrm{pta})_{3}$ and bpy.

\section{References}

1. T. Sekine and D. Dyrssen, J. Inorg. Nucl. Chem., 1967, 29, 1481.

2. L. Farbu, J. Alstad, and J. H. Augustson, J. Inorg. Nucl. Chem., 1974, 36, 2091.

3. T. Shigematsu, M. Tabushi, M. Matsui, and T. Honjo, Bull. Chem. Soc. Jpn., 1967, 40, 2807.

4. Y. Hasegawa, T. Yamada, and K. Nagata, Solvent Extr. Ion Exch., 1996, 14, 89.

5. Y. Hasegawa, T. Ohyama, and S. Katsuta, Bull. Chem. Soc. Jpn., 1995, 68, 3091.

6. I. Matsubayashi, E. Ishiwata, T. Shionoya, and Y. Hasegawa, Talanta, 2004, 63, 625 .

7. A. S. Kertes and E. E. Kassierer, Inorg. Chem., 1972, 11, 2108.

8. S. Nakamura and N. Suzuki, Inorg. Chim. Acta, 1986, 114, 101.

9. S. Nakamura and N. Suzuki, Polyhedron, 1988, 7, 155.

10. S. Yajima and Y. Hasegawa, Bull. Chem. Soc. Jpn., 1998, 71,2825

11. T. Ito and Y. Hasegawa, Solvent Extr. Res. Dev., Jpn., 2001, 8,47

12. Y. Hasegawa, M. Miratsu, and T. Kondo, Inorg. Chim. Acta, 2000, 303, 291.

13. Y. Hasegawa, M. Miratsu, and G. R. Choppin, Anal. Chim. Acta, 2001, 428, 149.

14. T. Sekine, Y. Hasegawa, and N. Ihara, J. Inorg. Nucl. Chem., 1973, 35, 3968. 